Check for updates

Cite this: RSC Adv., 2019, 9, 36058

\title{
Synthesis and properties of hyperbranched polymers for white polymer light-emitting diodes $\uparrow$
}

\author{
Xuefeng Li, (D) ab Haocheng Zhao, ${ }^{\text {cd }}$ Long Gao, ${ }^{b}$ Xiaoling Xie, ${ }^{\text {*a }}$ Weixuan Zhang, ${ }^{\text {ab }}$ \\ Mixue Wang, ${ }^{\mathrm{b}}$ Yuling Wu, (D) ${ }^{\mathrm{b}}$ Yanqin Miao, $\mathbb{D}^{\mathrm{b}}$ Hua Wang ${ }^{\mathrm{b}}$ and Bingshe $\mathrm{Xu}^{\mathrm{b}}$
}

In this work, a series of hyperbranched copolymers with fluorene-alt-carbazole as the branches, threedimensional-structured spiro[3.3]heptane-2,6-dispirofluorene (SDF) as the core, and iridium 1-(4bromophenyl)-isoquinoline (acetylacetone) (Ir(Brpiq) 2 acac) as the dimming group were synthesized by one-pot Suzuki polycondensation for white emission. All copolymers show great thermal stabilities and high hole-transporting ability due to the introduction of the carbazole unit. The hyperbranched structures for copolymers can suppress the interchain interactions efficiently, and help to form amorphous films. The fabricated polymer light-emitting devices (PLEDs) based on the above synthesized copolymers realize good white light emission, and achieve high electroluminescence (EL) performance. For example, for the optimized PLED, the maximum luminance and current efficiency reach $6210 \mathrm{~cd}$ $\mathrm{m}^{-2}$ and $6.30 \mathrm{~cd} \mathrm{~A}^{-1}$, respectively, indicating the synthesized hyperbranched copolymers have potential application in solution-processable white polymer light-emitting diodes.

Received 13th September 2019 Accepted 29th October 2019

DOI: $10.1039 / c 9 r a 07371 j$

rsc.li/rsc-advances advantages such as high contrast, high stability, low price and easy fabrication. ${ }^{\mathbf{1 2 - 1 4}} \mathrm{A}$ conventional approach to gain whitelight emission is to synthesize single molecule polymers with blue light emitting groups and complementary orange light emitting units or green and red light emitting units. ${ }^{\mathbf{1 3 , 1 5 , 1 6}}$ Therefore, in order to obtain white organic light emitting diodes (OLEDs), we introduce the broad spectral red light-emitting groups into the hyperbranched polymer. ${ }^{17}$

In this paper, we successfully synthesized the white emitting hyperbranched polymers by selecting fluorene-alt-carbazole as the branches, three-dimensional-structured spiro[3.3]heptane2,6-dispirofluorene (SDF) as the core, and the red phosphor group bis(1-phenyl-isoquinoline) (acetylacetonato)iridium(III) (Ir(Brpiq) ${ }_{2}$ acac) as a dimming functional group. It is found the synthesized hyperbranched polymers show a three-dimensional structure with very good morphological stability and strong fluorescence characteristics. And such three-dimensional structure can also effectively inhibit the entanglement of adjacent alkyl chains through its large steric hindrance, reducing the tight packing of molecular chains and the interaction between the various chromophores in the solid state, which is beneficial for achieving high-performance WPLEDs by suppressing the aggregation of the rigid conjugated polyfluorene material and improving the electroluminescence property. ${ }^{\mathbf{1 8 , 1 9}}$ Further, we fabricates the PLEDs by employing above synthesized copolymers as light-emitting layer. As we expected that all resulting PLEDs realize good white light emission, and achieve high electroluminescence (EL) performance. For example, for the optimized PLED, the maximum luminance and current efficiency reach $6210 \mathrm{~cd} \mathrm{~m}^{-2}$ and $6.30 \mathrm{~cd} \mathrm{~A}^{-1}$, respectively. 


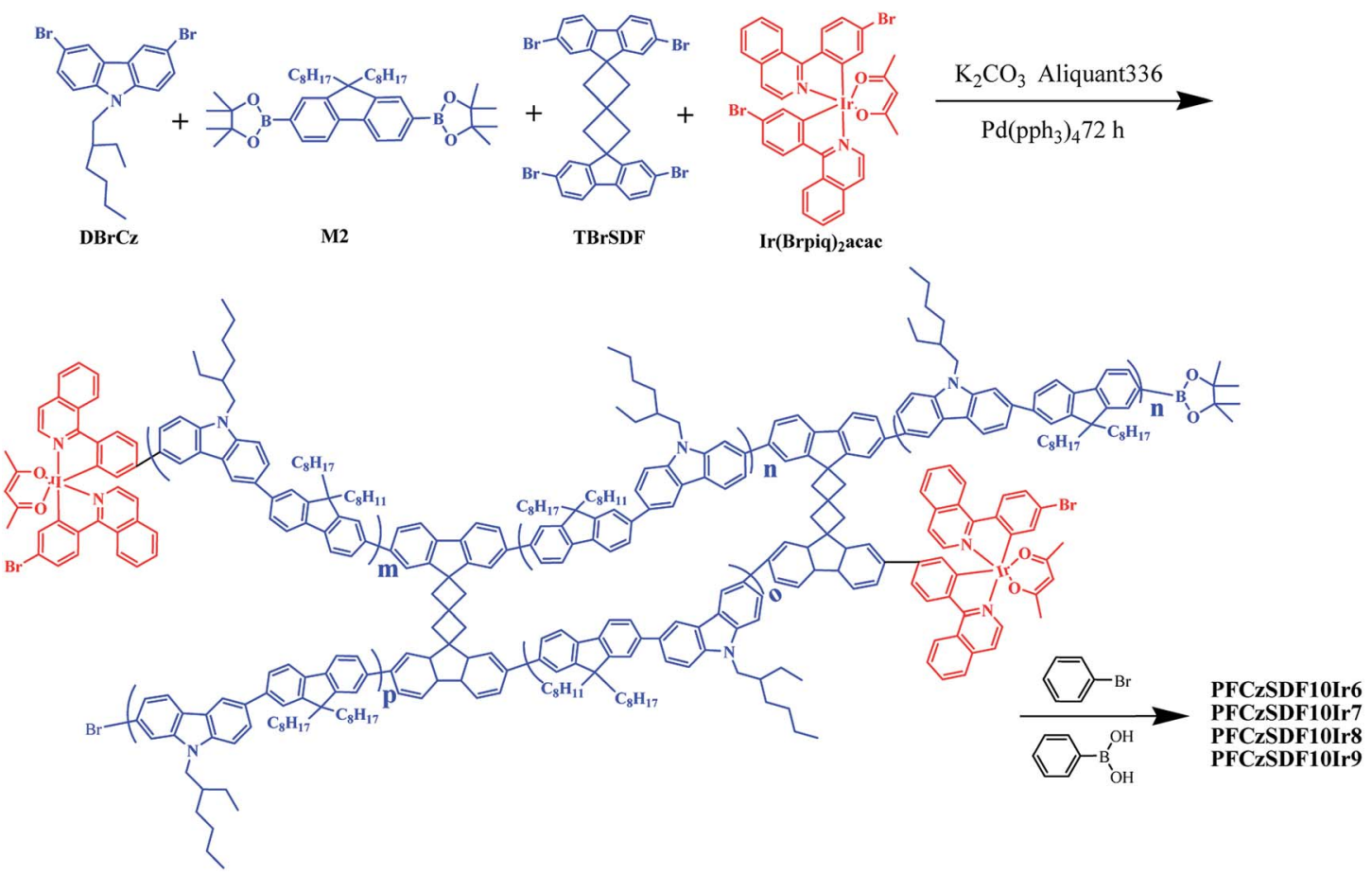

Scheme 1 Synthesis of the hyperbranched copolymers.

\section{Experimental section}

\section{Materials and characterization}

The detailed description about materials and measurements are shown in Section S1 in ESI. $\uparrow$ And the detailed process about OLEDs fabrication and testing are also displayed in Section S2 in ESI. $\dagger$

Syntheses. Spiro[3.3] heptane-2,6-di- $\left(2^{\prime}, 2^{\prime \prime}, 7^{\prime}, 7^{\prime \prime}\right.$-tetrabromospiro fluorene) (TBrSDF), ${ }^{\mathbf{1 8 2 0}}$ 3,6-dibromo- $N$-(2-ethylhexyl)-carbazole ( $\mathbf{D B r}$ $\mathbf{C z})^{21,22}$ and ( $\operatorname{Ir}(\text { Brpiq })_{2}$ acac) were synthesized according to the published literature.

\section{General procedure for the synthesis of copolymers}

PFCzSDF10Ir6-PFCzSDF10Ir9. To a solution of predetermi ned amount of the monomers (DBrCz, 9,9-dioctylfluorene-2,7bis(trimethyleneboronate) (M2), TBrSDF and $\operatorname{Ir}(\text { Brpiq })_{2}$ acac) in toluene $(20 \mathrm{~mL})$ was added an aqueous solution $(5 \mathrm{~mL})$ of potassium carbonate $(2 \mathrm{M})$ and a catalytic amount of $\mathrm{Pd}\left(\mathrm{PPh}_{3}\right)_{4}$ $(2.0 \mathrm{~mol} \%)$. Aliquat $336(1 \mathrm{~mL})$ in toluene $(5 \mathrm{~mL})$ was added as the phase transfer catalyst. The mixture was vigorously stirred at $90{ }^{\circ} \mathrm{C}$ for 3 days. Phenylboronic acid was then added to the reaction mixture, followed by stirring at $90{ }^{\circ} \mathrm{C}$ for an additional $12 \mathrm{~h}$. Finally, bromobenzene was added in the same way by heating for $12 \mathrm{~h}$ again. When cooled to room temperature, the reaction mixture was washed with $2 \mathrm{M} \mathrm{HCl}$ and water. The organic layer was separated, and the solution was added dropwise to excess methanol. The precipitates were collected by filtration, and dried under vacuum. The solid was Soxhlet extracted with acetone for $72 \mathrm{~h}$ and then passed through a short chromatographic column using toluene as the eluent to afford the copolymers.
PFCzSDF10Ir6. DBrCz (0.153 g, $0.35 \mathrm{mmol}), \mathbf{M} 2$ (0.354 g, 0.55 mmol), TBrSDF (0.071 g, $0.1 \mathrm{mmol})$ and $\operatorname{Ir}(\text { Brpiq })_{2}$ acac $(0.25 \mathrm{~mL}, 2$ $\left.\times 10^{-3} \mathrm{~mol} \mathrm{~L}^{-1}\right)$. Yield: $75.3 \%$. ${ }^{1} \mathrm{H}$ NMR $\left(\mathrm{CDCl}_{3}\right) \delta(\mathrm{ppm}): 7.88-7.57$ (-ArH-), 6.93-6.89 (-ArH-), 3.41-2.93 (- $\left.\mathrm{CH}_{2}^{-}\right), 2.21-1.89\left(-\mathrm{C}^{-} \mathrm{CH}_{2}-\right)$, $1.18-0.96\left(-\mathrm{CH}_{2}-\right), 0.93-0.55\left(-\mathrm{CH}_{3}\right)$.

PFCzSDF10Ir7. DBrCz (0.153 g, $0.35 \mathrm{mmol}), \mathbf{M} 2$ (0.354 g, 0.55 mmol), TBrSDF (0.071 g, $0.1 \mathrm{mmol})$ and $\operatorname{Ir}(\text { Brpiq })_{2}$ acac $(0.28 \mathrm{~mL}, 2$ $\left.\times 10^{-3} \mathrm{~mol} \mathrm{~L}^{-1}\right)$. Yield: $68.4 \% .{ }^{1} \mathrm{H}$ NMR $\left(\mathrm{CDCl}_{3}\right) \delta(\mathrm{ppm}): 7.89-7.56$ (-ArH-), 6.93-6.81 (-ArH-), 3.42-2.93 (- $\left.\mathrm{CH}_{2}{ }^{-}\right), 2.21-1.88\left(-\mathrm{C}-\mathrm{CH}_{2}{ }^{-}\right)$, $1.19-0.98\left(-\mathrm{CH}_{2}-\right), 0.94-0.60\left(-\mathrm{CH}_{3}\right)$.

PFCzSDF10Ir8. DBrCz (0.153 g, $0.35 \mathrm{mmol}), \mathbf{M} 2(0.354 \mathrm{~g}, 0.55$ $\mathrm{mmol})$, TBrSDF $(0.071 \mathrm{~g}, 0.1 \mathrm{mmol})$ and $\operatorname{Ir}(\text { Brpiq })_{2}$ acac $(0.40 \mathrm{~mL}, 2$ $\left.\times 10^{-3} \mathrm{~mol} \mathrm{~L}^{-1}\right)$. Yield: $72.7 \%$. ${ }^{1} \mathrm{H}$ NMR $\left(\mathrm{CDCl}_{3}\right) \delta(\mathrm{ppm}): 8.06-7.42$ (-ArH-), 6.94-6.77 (-ArH-), 3.45-3.02 (- $\left.\mathrm{CH}_{2}-\right)$, 2.24-1.87 (-C- $\left.\mathrm{CH}_{2}{ }^{-}\right)$, $1.19-0.95\left(-\mathrm{CH}_{2}-\right), 0.94-0.64\left(-\mathrm{CH}_{3}\right)$.

PFCzSDF10Ir9. DBrCz (0.153 g, $0.35 \mathrm{mmol})$, M2 (0.354 g, 0.55 mmol), TBrSDF $(0.071 \mathrm{~g}, 0.1 \mathrm{mmol})$ and $\operatorname{Ir}(\text { Brpiq })_{2}$ acac $(0.45 \mathrm{~mL}, 2$ $\left.\times 10^{-3} \mathrm{~mol} \mathrm{~L}^{-1}\right)$. Yield: $71.5 \%$. ${ }^{1} \mathrm{H}$ NMR $\left(\mathrm{CDCl}_{3}\right) \delta(\mathrm{ppm}): 7.98-7.48$ (-ArH-), 6.93-6.78 (-ArH-), 3.39-3.02 (- $\left.\mathrm{CH}_{2}-\right)$, 2.21-1.75 (-C- $\left.\mathrm{CH}_{2}-\right)$, $1.22-0.88\left(-\mathrm{CH}_{2}-\right), 0.86-0.45\left(-\mathrm{CH}_{3}\right)$.

Table 1 Polymerization and characterizations results of the polymers

GPC

\begin{tabular}{llllllll} 
Copolymers & $n_{\text {DBrCz }}$ & $n_{\mathbf{M} 2}$ & $n_{\text {TBrSDF }}$ & $n_{\text {red }}$ & Yield (\%) & $M_{\mathrm{n}}$ & PDI \\
\hline
\end{tabular}

$\begin{array}{lllllllll}\text { PFCzSDF10Ir6 } & 0.35 & 0.55 & 0.10 & 6 \times 10^{-4} & 75.3 & 9234 & 1.94\end{array}$ $\begin{array}{lllllllll}\text { PFCzSDF10Ir7 } & 0.35 & 0.55 & 0.10 & 7 \times 10^{-4} & 68.4 & 11 & 193 & 3.67\end{array}$ $\begin{array}{llllllll}\text { PFCzSDF10Ir8 } & 0.35 & 0.55 & 0.10 & 8 \times 10^{-4} & 72.7 & 9936 & 3.77\end{array}$ $\begin{array}{llllllll}\text { PFCzSDF10Ir9 } & 0.35 & 0.55 & 0.10 & 9 \times 10^{-4} & 71.5 & 9588 & 1.29\end{array}$ 


\section{Results and discussion}

Synthesis and characterization

As shown in Scheme 1, a series of hyperbranched copolymers based on $\mathrm{N}$-alkyl and 9-C-alkyl substituted 3,6-carbazole-co-2,7fluorene branches with SDF (10 mol\%) as the branch point were synthesized by one-pot Suzuki polycondensation in relatively high yields. To obtain efficiently white-light emission, the phosphor red light-emitting unit of $\operatorname{Ir}\left(\right.$ Brpiq) ${ }_{2}$ acac was incorporated into the main chain with the feed ratios of $0.06 \mathrm{~mol} \%$, $0.07 \mathrm{~mol} \%, 0.08 \mathrm{~mol} \%$ and $0.09 \mathrm{~mol} \%$, and the corresponding copolymers are named as PFCzSDF10Ir6, PFCzSDF10Ir7, PFCzSDF10Ir8 and PFCzSDF10Ir9, respectively. The synthetic and structural results of PPFCzSDF10Ir6-PFCzSDF10Ir9 are summarized in Table 1.

The functional groups for Suzuki polycondensation were bromine and pinacol borate. Thus, the fluorene and carbazole monomers distributed alternately in the synthesized polymer branches. Because of the same feed ratios of monomers DBrCz, M2 and TBrSDF for copolymers PFCzSDF10Ir6-PFCzSDF10Ir9, their ${ }^{1} \mathrm{H}$ NMR spectra were quite similar (Fig. S4 in ESI $\dagger$ ). The proton signals of $\operatorname{Ir}(\mathbf{p i q})_{2}$ acac have little effect because of its low content, revealing the similar backbone structures of the copolymers. The number-average molecular weights $\left(M_{\mathrm{n}}\right)$ of the copolymers determined by gel permeation chromatography (GPC) ranged from 9234 to 11193 with a polydispersity index (PDI) from 1.94 to 3.77 . The resulting copolymers are readily

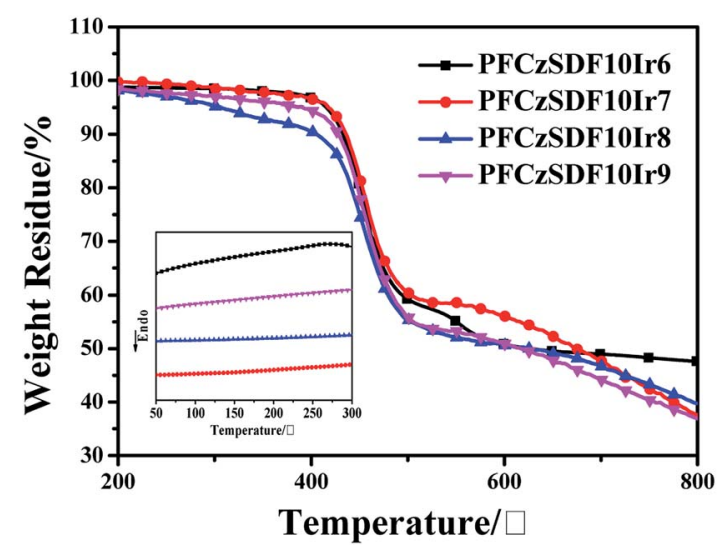

Fig. 1 TGA and DSC (inset) curves of the copolymers in nitrogen atmosphere with a heating rate of $10{ }^{\circ} \mathrm{C} \min ^{-1}$ and $5{ }^{\circ} \mathrm{C} \min ^{-1}$, respectively. soluble in common organic solvents such as trichloromethane $\left(\mathrm{CHCl}_{3}\right)$, tetrahydrofuran (THF) and toluene.

\section{Thermal properties}

The thermogravimetric analysis (TGA) and (differential scanning calorimetry) DSC data of the hyperbranched polymers are shown in Fig. 1 and Table 2. The onset decomposition temperatures ( $T_{\mathrm{d}}$, measured at a $5 \%$ weight loss) range from 300 to $416{ }^{\circ} \mathrm{C}$ under nitrogen. The high thermal stability is ascribed to the presence of a large amount of carbazole groups and three dimensional structure of the hyperbranched polymers, which are known to exhibit excellent thermal and chemical
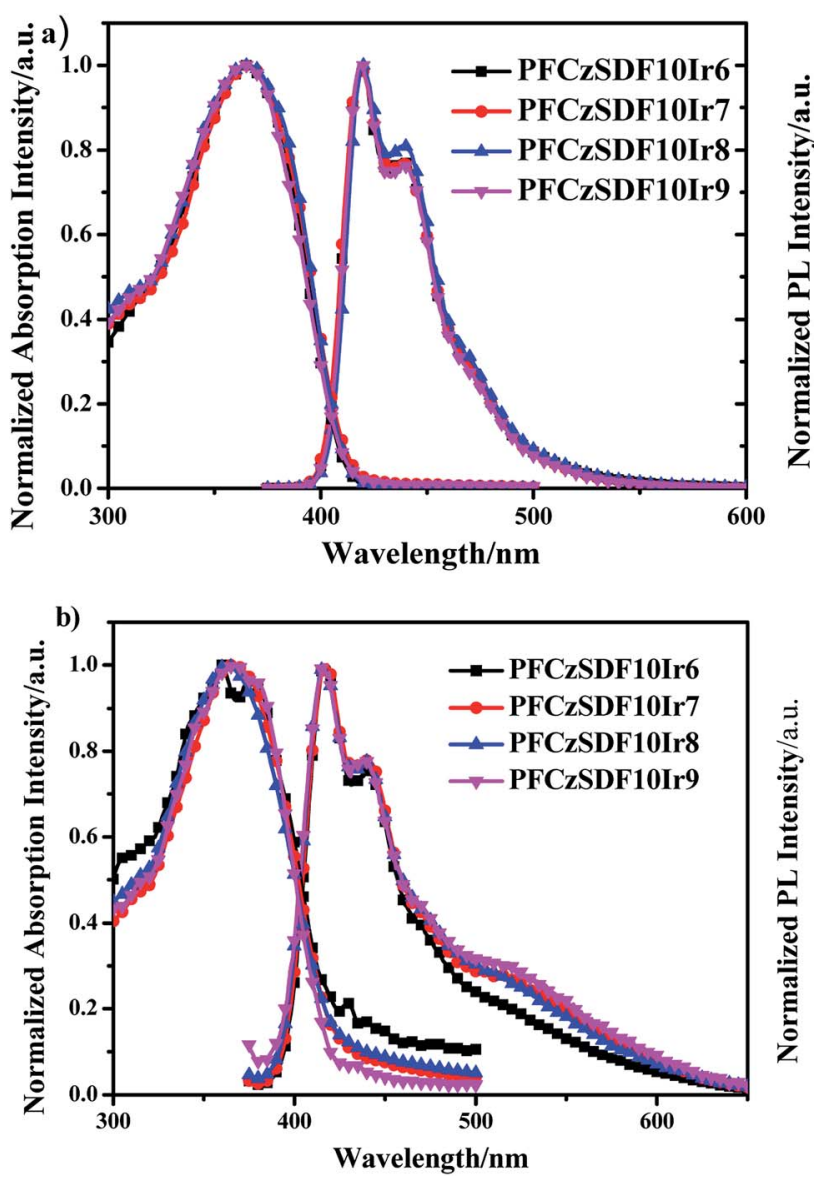

Fig. 2 The UV-vis absorption and PL spectra of the hyperbranched polymers: (a) in $\mathrm{CHCl}_{3}$ solution $\left(10^{-5} \mathrm{M}\right)$ and (b) in solid film.

Table 2 Thermal and photophysical properties of the copolymers

\begin{tabular}{|c|c|c|c|c|c|c|}
\hline \multirow[b]{2}{*}{ Copolymers } & \multirow[b]{2}{*}{$T_{\mathrm{d}}\left({ }^{\circ} \mathrm{C}\right)$} & \multirow[b]{2}{*}{$T_{\mathrm{g}}\left({ }^{\circ} \mathrm{C}\right)$} & \multicolumn{2}{|c|}{ Dilute solution } & \multicolumn{2}{|l|}{ Solid film } \\
\hline & & & $\lambda_{\mathrm{abs}}(\mathrm{nm})$ & $\lambda_{\mathrm{PL}}(\mathrm{nm})$ & $\lambda_{\text {abs }}(\mathrm{nm})$ & $\lambda_{\mathrm{PL}}(\mathrm{nm})$ \\
\hline PFCzSDF10Ir7 & 420 & 150 & 365 & 419,438 & 366 & $416,440,516$ \\
\hline PFCzSDF10Ir8 & 304 & 175 & 365 & 419,438 & 362 & $416,439,515$ \\
\hline PFCzSDF10Ir9 & 391 & 149 & 364 & 419,439 & 366 & $416,438,519$ \\
\hline
\end{tabular}




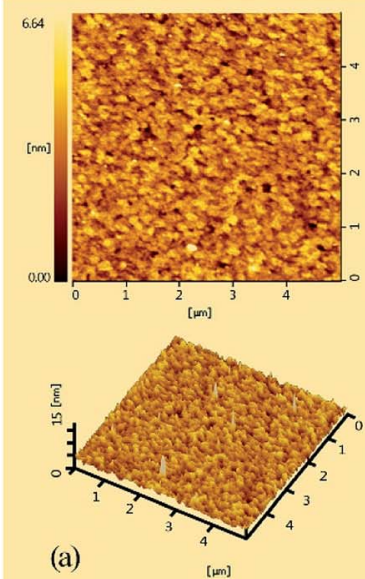

$[\mu m]$
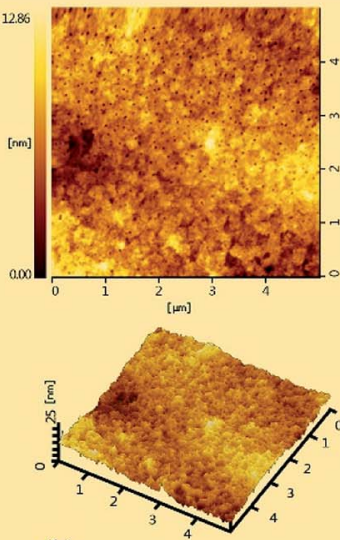

(b)
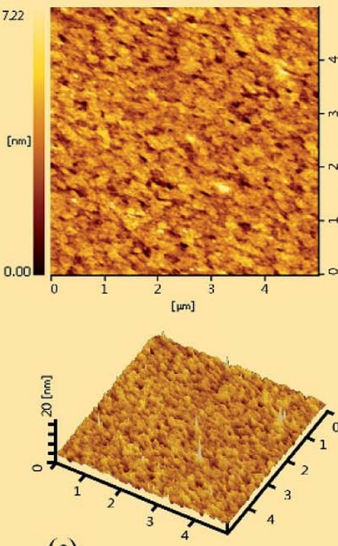

(c)
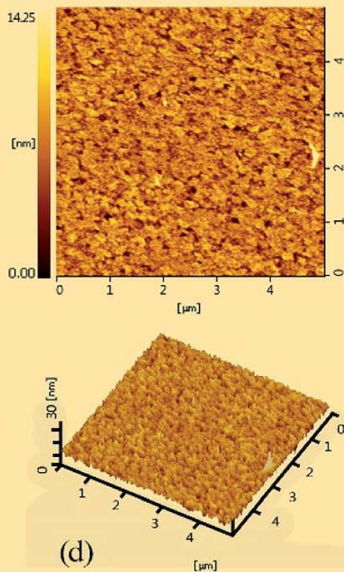

Fig. 3 AFM images $(5 \times 5 \mu \mathrm{m}$ ) of the copolymer films: (a) for PFCzSDF10lr6, (b) for PFCzSDF10Ir7, (c) for PFCzSDF10lr8, and (d) for PFCzSDF10Ir9.

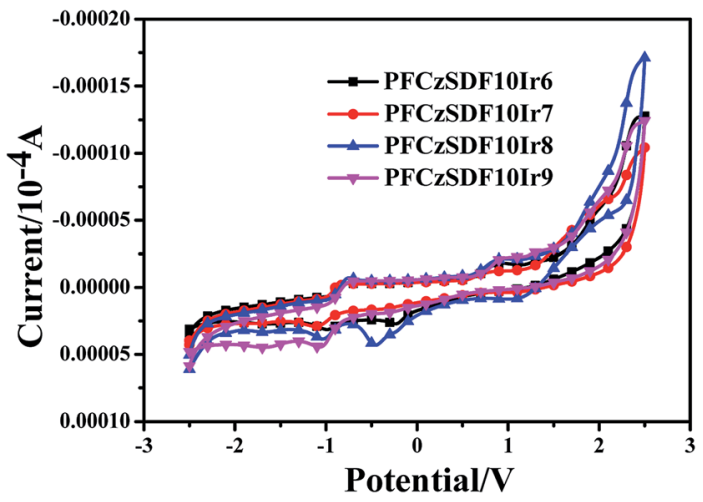

Fig. 4 Cyclic voltammograms curves of the hyperbranched polymers. stabilities. ${ }^{23}$ The relatively high glass transition temperatures ( $T_{\mathrm{g}}$, in inset of Fig. 1) of around $150{ }^{\circ} \mathrm{C}$ are found from the DSC curves, which indicates the good morphological stabilities of the copolymers. The high $T_{\mathrm{g}}$ could be attributed to their rigid hyperbranched structures and the introduction of carbazole unit to the copolymer backbones.

\section{Photophysical properties}

The UV-vis absorption of $\mathbf{I r}(\mathbf{p i q})_{2}$ acac and the PL spectra of fluorene-alt-carbazole copolymer (PFCz) are shown in Fig. S5. $\dagger$ The absorption of $\mathbf{I r}(\mathbf{p i q})_{2}$ acac and the emission of PFCz show good spectral overlap, indicating the efficient FRET from the $\mathrm{PFCz}$ segment to $\mathbf{I r}(\mathbf{p i q})_{2}$ acac unit can be expected. The normalized UV-

Table 3 Electrochemical properties of the hyperbranched polymers

\begin{tabular}{llllrl}
\hline Copolymers & $\lambda_{\text {abs(onset) }}(\mathrm{nm})$ & $E_{\mathrm{g}}(\mathrm{eV})$ & $E_{\text {onset/ox }}(\mathrm{V})$ & HOMO (eV) & LUMO (eV) \\
\hline PFCZSDF10Ir6 & 404 & 3.07 & 0.93 & -5.43 & -2.36 \\
PFCzSDF10Ir7 & 405 & 3.06 & 0.86 & -5.36 & -2.30 \\
PFCZSDF10Ir8 & 406 & 3.05 & 0.90 & -5.40 & -2.35 \\
PFCzSDF10Ir9 & 405 & 3.06 & 0.94 & -5.44
\end{tabular}
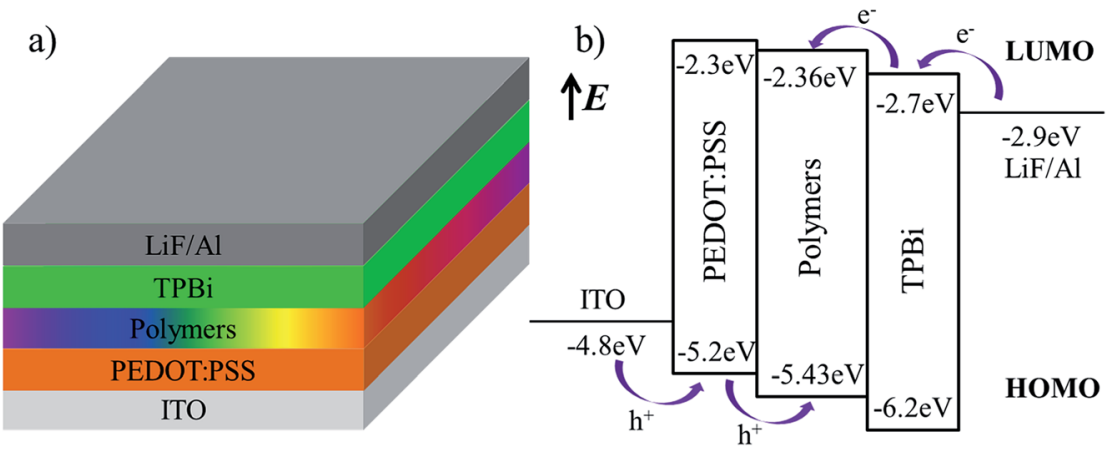

Fig. 5 The device structure (a) and energy-level (b) diagrams of the devices. 

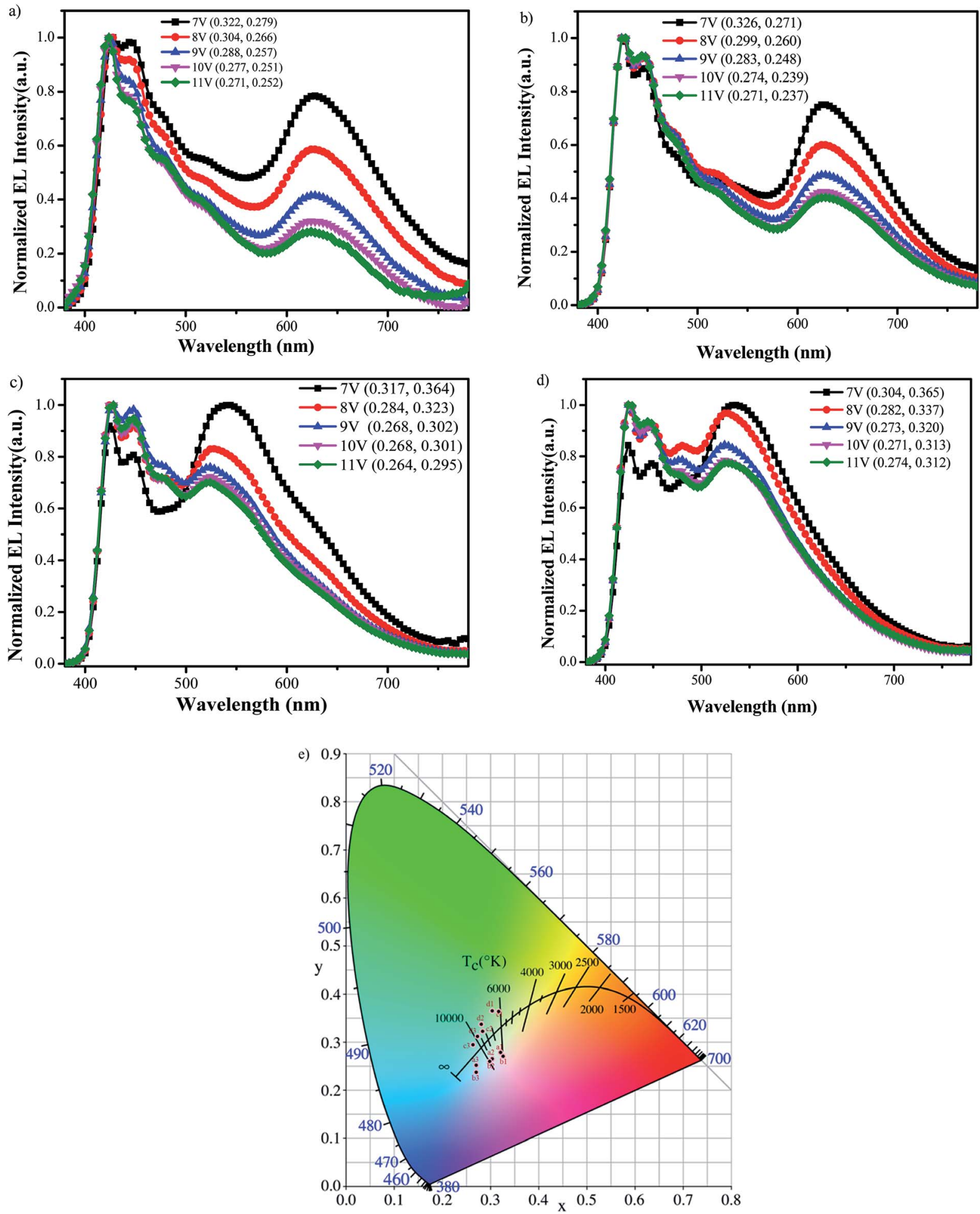

Fig. 6 Electroluminescence spectra of the hyperbranched polymer at different voltages PFCzSDF10Ir6 (a), PFCzSDF10Ir7 (b), PFCzSDF10Ir8 (c) and PFCzSDF10Ir9 (d) and CIE graph of all polymers at voltages for $7 \mathrm{~V}, 8 \mathrm{~V}$, and $11 \mathrm{~V}(\mathrm{e})$.

vis absorption and photoluminescence (PL) spectra of the copolymers in dilute solution are shown in Fig. 2. The absorption bands at around $365 \mathrm{~nm}$ are due to the $\pi-\pi^{*}$ transitions of poly(fluorene-alt-carbazole) backbones,${ }^{24}$ which are blue-shifted about $15 \mathrm{~nm}$ compared with the fluorene-based hyperbranched polymer with SDF of $10 \mathrm{~mol} \%$. This notable hypochromatic shift is attributable to the interruption of the conjugation of the copolymer backbone by the introduction of the 3,6-carbazole 
linkage. In PL spectra, the copolymers exhibit emission bands at $420 \mathrm{~nm}$ and a slight vibronic shoulder at $440 \mathrm{~nm}$, which can be attributed to $0-0$ and $0-1$ intrachain singlet transitions in the poly(fluorene-alt-carbazole) branches. ${ }^{25}$ The PL spectra showed about $5 \mathrm{~nm}$ blue-shift respect to that of the fluorene-based copolymer because of the decreased conjugated length in these fluorene-alt-carbazole based copolymers.

A phosphorescent red group $\mathbf{I r}(\mathbf{p i q})_{2}$ acac with high internal quantum efficiency as a adjusting group to be introduced into the hyperbranched polymer chain, no distinct absorption or emission peaks of $\operatorname{Ir}\left(\right.$ piq) ${ }_{2}$ acac unit can be observed in the spectra because of its relatively lower content in the polymers, and the Förster resonance energy transfer (FRET) is exclusively intrachain in dilute solution. ${ }^{26}$

In films, the hyperbranched polymers exhibit UV-vis absorption bands at around $365 \mathrm{~nm}$ owing to the $\pi-\pi^{*}$ transitions of the poly-(fluorene-alt-carbazole) backbones (Fig. $2 \mathrm{~b}$ and Table 2). In PL spectra, the maximum emission bands of copolymers are at about $416 \mathrm{~nm}$, along with a shoulder at around $439 \mathrm{~nm}$, showing no obvious bathochromic shift with respect to those in dilute solution, indicating that the hyperbranched structure can effectively avoid the red shift caused by intermolecular aggregation. ${ }^{25,27,28}$

\section{Film morphology}

The morphology of copolymers films, which is a key factor for PLEDs fabrication, was investigated by atomic force microscopy (AFM) at a tapping mode. Fig. 3 shows the AFM images of PPFCzSDF10Ir6-PFCzSDF10Ir9 films prepared by spin-coating chlorobenzene solutions of the copolymers $\left(10^{-5} \mathrm{M}\right)$ on the full ITO glass. The root-mean-square (RMS) roughness values of hyperbranched polymers are $0.96 \mathrm{~nm}, 1.91 \mathrm{~nm}, 1.00 \mathrm{~nm}$, and $2.06 \mathrm{~nm}$, respectively. All the films show flat and smooth surface without any pinhole defects. The results imply that the threedimensional structured SDF branch point can help to form homogeneous films with good quality. ${ }^{29}$ The uniform amorphous morphology is favorable for PLEDs fabrication.

\section{Electrochemical characteristics}

The electrochemical behaviors of the resulting hyperbranched polymers were investigated by cyclic voltammetry (CV), as shown in Fig. 4 and Table 3 . The oxidation potentials $\left(E_{\mathrm{Ox}}\right)$ vary slightly from 0.86 to $0.93 \mathrm{~V}$. The HOMO levels of polymers are calculated according to the empirical formulas $E_{\mathrm{HOMO}}=-\left(E_{\mathrm{Ox}}+4.5\right)(\mathrm{eV}){ }^{5}$ they are at about $-5.40 \mathrm{eV}$. The lowest unoccupied molecular orbital (LUMO) levels are deduced from the HOMO levels and the optical band gaps $\left(E_{\mathrm{g}}\right)$ determined from the onset value of the absorption spectrum in film in the long-wavelength direction $\left(E_{\mathrm{g}}\right.$ $\left.=1240 / \lambda_{\text {edge }}\right)$, and they are at $-2.30 \mathrm{eV}$ to $-2.38 \mathrm{eV}$. The HOMO levels of the hyperbranched polymers are slightly deeper than the work function $(-5.2 \mathrm{eV})$ of PEDOT:PSS, which imply the facile hole injection from PEDOT:PSS to hyperbranched polymers emission layer (EML) can be expected..$^{30}$ On the other hand, the LUMO levels of the hyperbranched polymers are slightly shallower than that $(-2.7 \mathrm{eV})$ of electron transporting 1,3,5-tri(1phenyl-1H-benzo[ $d]$ imidazol-2-yl)phenyl (TPBi), indicating that the barrier for electron injection is relatively small from electron transporting layer to hyperbranched polymer EML.

\section{Electroluminescent properties}

Based on good photoelectric performance and suitable energy level for above hyperbranched polymers, we further evaluate the their EL performance by fabricating the PLEDs with the configuration of ITO/PEDOT:PSS (40 nm)/polymers $(50 \mathrm{~nm}) /$ TPBi $(45 \mathrm{~nm}) / \mathrm{LiF}(1 \mathrm{~nm}) / \mathrm{Al}(150 \mathrm{~nm})$. The device structure and energy-level diagrams of all devices are shown in Fig. 5a and $\mathrm{b}$, respectively. In these devise, ITO and $\mathrm{Al}$ are used as anode and cathode, respectively; PEDOT:PSS and TPBi are used as hole transport layer and electron transport layer, respectively; $50 \mathrm{~nm}$ thick polymers layer is used as EML, and $1 \mathrm{~nm}$-thick LiF layer used as electron injection layer., ${ }^{\mathbf{1 , 3 1 - 3 5}}$

Fig. 6a-d shows the EL spectra for all polymers-based PLEDs at voltages varying from 7 to $11 \mathrm{~V}$. It can be seen that all resulting PLEDs with PFCzSDF10Ir6, PFCzSDF10Ir7, PFCzSDF10Ir8, PFCzSDF10Ir9 as realize good white emission with CIE coordinate of at $(0.27,0.25),(0.27,0.24),(0.26,0.30)$, and $(0.27,0.31)$ at $11 \mathrm{~V}$, respectively, and the EL spectra for these PLEDs all contain two main emission peaks located at blue and orange-red wavebands, which are corresponding to the emissions of poly(fluorene-altcarbazole) branches and red dimming phosphor group (Ir(piq) $)_{2^{-}}$ acac). This is ascribed to the incomplete Förster energy transfer in intra-, and interchain interaction of polymer layer from $\mathbf{P F C z}$ segment to $\operatorname{Ir}(\text { piq })_{2}$ acac unit. With the $\operatorname{Ir}(\text { Brpiq })_{2}$ acac feed ratios from $0.06 \mathrm{~mol} \%, 0.07 \mathrm{~mol} \%, 0.08 \mathrm{~mol} \%$ to $0.09 \mathrm{~mol} \%$ in synthesis processes, corresponding to PFCzSDF10Ir6, PFCzSDF10Ir7, PFCzSDF10Ir8 and PFCzSDF10Ir9, respectively, the orange-red wavebands from (Ir(piq) $)_{2}$ acac) in EL spectra present an increasing trend, indicating the EL spectra of polymers-based PLEDs can be realized and adjusted by simply changing the $\operatorname{Ir}(\text { Brpiq })_{2}$ acac feed ratios in synthesis processes. For individual PLED, we can see that under low voltage, the longer wavelength orange-red emission in EL spectra is the strongest, and with the increase of drive voltage from $7 \mathrm{~V}$ to $11 \mathrm{~V}$, the longer wavelength orange-red emission reduced gradually, and keep almost overlapping EL spectra at 10-11 V for all PLEDs. This is because the exciton energy can easily transfer to lower energy level of $\mathbf{I r}(\mathbf{p i q})_{2}$ acac, leading to stronger orange-red emission form $\operatorname{Ir}(\text { piq })_{2}$ acac,

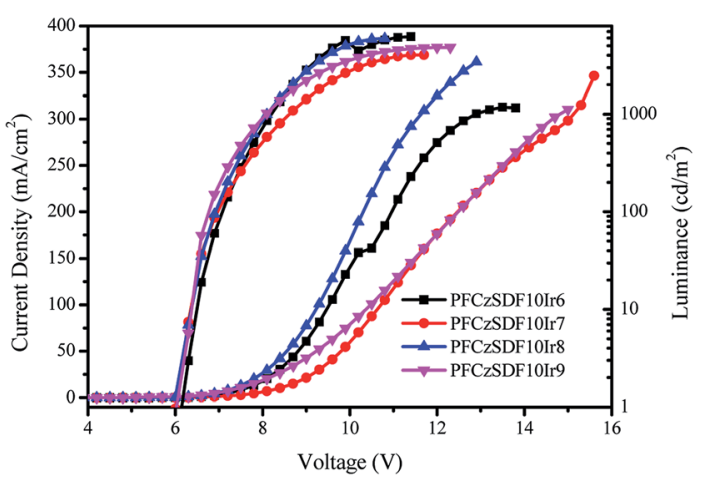

Fig. 7 Current density-voltage-brightness $(J-V-L)$ curves characteristics of hyperbranched polymers light emitting devices. 
Table 4 EL Performances of the PLEDs

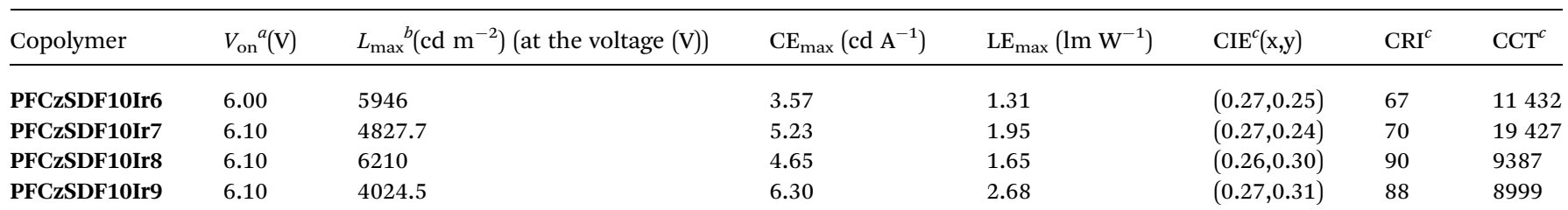

${ }^{a}$ Turn-on voltage (at $1 \mathrm{~cd} \mathrm{~m}^{-2}$ ). ${ }^{b}$ Maximum luminance at applied voltage. ${ }^{c} \mathrm{CIE}$, CRI and CCT values measured at a voltage of $11 \mathrm{~V}$ for devices a-d.

but with the increase of drive voltage, the site of $\operatorname{Ir}(\mathbf{p i q})_{2}$ acac can be easily saturated, inducing a reduced orange-red emission in EL spectra. The difference in the PL and EL spectra imply that different mechanisms should be involved. In photoluminescence excitation (PLE), the PFCz moiety is in a single excited state and the energy is transferred to the Ir(III) complex. In electroluminescent excitation, electrons are injected from the cathode in the device, and holes are injected from the anode and then trapped by the $\operatorname{Ir}(\mathrm{III})$ complex. The results reveal that the intra-, interchain FRET from PFCz unit to $\operatorname{Ir}(\mathbf{p i q})_{2}$ acac and the charge trapping of $\operatorname{Ir}(\mathbf{p i q})_{2}$ acac happen simultaneously in the electroluminescence process.

Fig. 7 shows the current density-voltage-luminance $(J-V-L)$ characteristics curves of all hyperbranched polymers-based devices, and the basic electroluminescence properties of the device are summarized in Table 4 . It can be seen that the maximum luminance $\left(\sim 6210 \mathrm{~cd} \mathrm{~m}^{-2}\right)$ for PFCzSDF10Ir8-based device and the maximum current efficiency $\left(\sim 6.30 \mathrm{~cd} \mathrm{~A}^{-1}\right)$ of PFCzSDF10Ir9-based device are obtained. Further investigations on the optimization of the device performance and the synthesis of hyperbranched polymers with different structure and color groups are ongoing in our laboratory.

\section{Conclusions}

In this work, a series of hyperbranched copolymers with fluorenealt-carbazole as the branches, three-dimensional-structured spiro [3.3] heptane-2,6-dispirofluorene (SDF) as the core, and iridium 1(4-bromophenyl)-isoquinoline (acetylacetone) $\left(\operatorname{Ir}(\mathrm{Brpiq})_{2} \mathrm{acac}\right)$ as dimming group were synthesized by one-pot Suzuki polycondensation for white emission. All synthesized hyperbranched polymers show a three-dimensional structure with very good morphological stability and strong fluorescence characteristics. And such three-dimensional structure can also effectively inhibit the entanglement of adjacent alkyl chains through its large steric hindrance, reducing the tight packing of molecular chains and the interaction between the various chromophores in the solid state. The fabricated polymer light-emitting devices (PLEDs) based above synthesized copolymers realize good white light emission, and achieve high electroluminescence (EL) performance. For example, for the optimized PLED, the maximum luminance and current efficiency reach $6210 \mathrm{~cd} \mathrm{~m}^{-2}$ and $6.30 \mathrm{~cd}$ $\mathrm{A}^{-1}$, respectively. These results indicate that the hyperbranched polymers using SDF as the core and fluorene-alt-carbazole as the branches and phosphorescent adjusting group could be promising candidates as white-emitting materials with high efficiency.

\section{Conflicts of interest}

The authors declare no competing financial interest.

\section{Acknowledgements}

The authors are grateful to the "the National Natural Science Foundation of China $(61705158$, 61605138, 61605137, 61775155, 61705156), Shanxi Province Natural Science Foundation (201601D202030, 201601D021018, 201601D011031, 201801D221102); and Scientific and Technological Innovation Programs of Higher Education Institutions in Shanxi (2019L0302, 2016134, 2016135, 201802111).

\section{Notes and references}

1 T. Guo, R. Guan, J. Zou, J. Liu, L. Ying, W. Yang, H. Wu and Y. Cao, Polym. Chem., 2011, 2, 2193.

2 T. Guo, L. Yu, Y. Yang, Y. Li, Y. Tao, Q. Hou, L. Ying, W. Yang, H. Wu and Y. Cao, J. Lumin., 2015, 167, 179-185.

3 S. H. Hwang, C. D. Shreiner, C. N. Moorefield and G. R. Newkome, New J. Chem., 2007, 31, 1192.

4 F. Liu, J. Q. Liu, R.-R. Liu, X.-Y. Hou, L.-H. Xie, H.-B. Wu, C. Tang, W. Wei, Y. Cao and W. Huang, J. Polym. Sci., Part A: Polym. Chem., 2009, 47, 6451-6462.

5 Y. Wu, J. Li, W. Liang, J. Yang, J. Sun, H. Wang, X. Liu, B. Xu and W. Huang, RSC Adv., 2015, 5, 49662-49670.

6 J. Sun, J. Yang, C. Zhang, H. Wang, J. Li, S. Su, H. Xu, T. Zhang, Y. Wu, W.-Y. Wong and B. Xu, New J. Chem., 2015, 39, 5180-5188.

7 L. R. Tsai and Y. Chen, J. Polym. Sci., Part A: Polym. Chem., 2007, 45, 4465-4476.

8 A. Pfaff and A. H. E. Müller, Macromolecules, 2011, 44, 12661272.

9 B. Bao, L. Yuwen, X. Zhan and L. Wang, J. Polym. Sci., Part A: Polym. Chem., 2010, 48, 3431-3439.

10 L. R. Tsai and Y. Chen, Macromolecules, 2008, 41, 5098-5106. 11 D. Konkolewicz, C. K. Poon, A. Gray-Weale and S. Perrier, Chem. Commun., 2011, 47, 239-241.

12 J. Liu, Y. Cheng, Z. Xie, Y. Geng, L. Wang, X. Jing and F. Wang, Adv. Mater., 2008, 20, 1357-1362.

13 L. Ying, C. L. Ho, H. Wu, Y. Cao and W. Y. Wong, Adv. Mater., 2014, 26, 2459-2473.

14 S. J. Su and X. L. Li, White Organic Light-Emitting Diodes, 2016. 
15 X. H. Zhu, J. Peng, Y. Cao and J. Roncali, Chem. Soc. Rev., 2011, 40, 3509-3524.

16 B. Zhang, G. Tan, C. S. Lam, B. Yao, C. L. Ho, L. Liu, Z. Xie, W. Y. Wong, J. Ding and L. Wang, Adv. Mater., 2012, 24, 1873-1877.

17 Y. Miao, X. Wei, L. Gao, K. Wang, B. Zhao, Z. Wang, B. Zhao, H. Wang, Y. Wu and B. Xu, Nanophotonics, 2019, 8, 17831794.

18 Z. Wang, L. Zheng, J. Wang and W. Du, Complexity, 2019, 4031795.

19 W. Y. Wong, Coord. Chem. Rev., 2005, 249, 971-997.

20 Z. Wang, J. Wang, W. Cai, J. Zhou, W. Du, J. Wang, G. He and H. He, Complexity, 2019, 1564243.

21 J. Kim, S. H. Park, S. Cho, Y. Jin, J. Kim, I. Kim, J. S. Lee, J. H. Kim, H. Y. Woo, K. Lee and H. Suh, Polymer, 2010, 51, 390-396.

22 H. Wang, J. T. Ryu and Y. Kwon, J. Appl. Polym. Sci., 2011, 119, 377-386.

23 T. Sudyoadsuk, P. Moonsin, N. Prachumrak, S. Namuangruk, S. Jungsuttiwong, T. Keawin and V. Promarak, Polym. Chem., 2014, 5, 3982.

24 J. Li, R. Liu, Z. Zhao and Z. Zhou, J. Mater. Sci.: Mater. Electron., 2014, 25, 1970-1975.
25 J. Yang, C. Jiang, Y. Zhang, R. Yang and Y. Y. Cao, Macromolecules, 2004, 37, 1211-1218.

26 L. Ying, Y. Xu, W. Yang, L. Wang, H. Wu and Y. Cao, Org. Electron., 2009, 10, 42-47.

27 Z. Wang, P. Lu, S. Xue, C. Gu, Y. Lv, Q. Zhu, H. Wang and Y. Ma, Dyes Pigm., 2011, 91, 356-363.

28 W. Hua, X. U. Yang, T. Tsuboi, X. U. Huixia, W. U. Yuling, Z. Zhang, Y. Miao, Y. Hao and X. Liu, Org. Electron., 2013, 14, 827-838.

29 Y. Wu, J. Li, W. Liang, J. Yang, J. Sun, H. Wang, X. Liu, B. Xu and W. Huang, New J. Chem., 2015, 39, 5977-5983.

30 M. Zhu, Y. Li, J. Miao, B. Jiang, C. Yang, H. Wu, J. Qin and Y. Cao, Org. Electron., 2014, 15, 1598-1606.

31 Y. Miao, K. Wang, B. Zhao, L. Gao, P. Tao, X. Liu, Y. Hao, H. Wang, B. Xu and F. Zhu, Nanophotonics, 2018, 7, 295-304. 32 Y. Miao, P. Tao, K. Wang, H. Li, B. Zhao, L. Gao, H. Wang, B. Xu and Q. Zhao, ACS Appl. Mater. Interfaces, 2017, 9, 37873-37882.

33 Y. Miao, K. Wang, L. Gao, B. Zhao, H. Wang, F. Zhu, B. Xu and D. Ma, J. Mater. Chem. C, 2018, 6, 8122-8134.

34 P. Tao, Y. Miao, H. Wang, B. Xu and Q. Zhao, Chem. Rec., 2019, 19, 1531-1561.

35 Y. Wu, X. Li, H. Zhao, J. Li, Y. Miao, H. Wang, F. Zhu and B. Xu, Org. Electron., 2020, 76, 105487. 